\title{
Influence of Processing Method on the Grain Boundary Character Distribution and Network Connectivity
}

\author{
A.J. Schwartz, M. Kumar, W.E. King
}

This article was submitted to Materials Research Society 1999 Fall Meeting, Boston, MA, November 29-December 3, 1999

\section{December 20, 1999}

U.S. Department of Energy

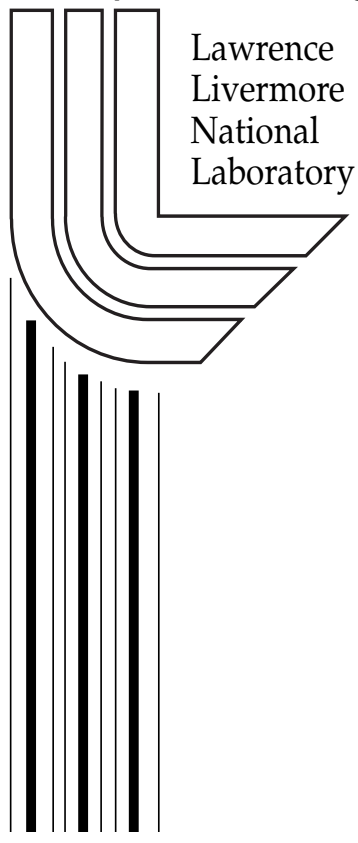




\section{DISCLAIMER}

This document was prepared as an account of work sponsored by an agency of the United States Government. Neither the United States Government nor the University of California nor any of their employees, makes any warranty, express or implied, or assumes any legal liability or responsibility for the accuracy, completeness, or usefulness of any information, apparatus, product, or process disclosed, or represents that its use would not infringe privately owned rights. Reference herein to any specific commercial product, process, or service by trade name, trademark, manufacturer, or otherwise, does not necessarily constitute or imply its endorsement, recommendation, or favoring by the United States Government or the University of California. The views and opinions of authors expressed herein do not necessarily state or reflect those of the United States Government or the University of California, and shall not be used for advertising or product endorsement purposes.

This is a preprint of a paper intended for publication in a journal or proceedings. Since changes may be made before publication, this preprint is made available with the understanding that it will not be cited or reproduced without the permission of the author.

This report has been reproduced

directly from the best available copy.

Available to DOE and DOE contractors from the

Office of Scientific and Technical Information

P.O. Box 62, Oak Ridge, TN 37831

Prices available from (423) 576-8401

http://apollo.osti.gov/bridge/

Available to the public from the

National Technical Information Service

U.S. Department of Commerce

5285 Port Royal Rd.,

Springfield, VA 22161

http://www.ntis.gov/

OR

Lawrence Livermore National Laboratory

Technical Information Department's Digital Library

http://www.llnl.gov/tid/Library.html 


\title{
INFLUENCE OF PROCESSING METHOD ON THE GRAIN BOUNDARY CHARACTER DISTRIBUTION AND NETWORK CONNECTIVITY
}

\author{
ADAM J. SCHWARTZ, MUKUL KUMAR, AND WAYNE E. KING \\ University of California, Lawrence Livermore National Laboratory, Chemistry and Materials \\ Science Directorate, Livermore, CA 94550, USA, ajschwartz@1lnl.gov
}

\begin{abstract}
There exists a growing body of literature that correlates the fraction of "special" boundaries in a microstructure, as described by the Coincident Site Lattice Model, to properties such as corrosion resistance, intergranular stress corrosion cracking, creep, etc. Several studies suggest that the grain boundary character distribution (GBCD), which is defined in terms of the relative fractions of "special" and "random" grain boundaries, can be manipulated through thermomechanical processing. This investigation evaluates the influence of specific thermomechanical processing methods on the resulting GBCD in FCC materials such as oxygenfree electronic (ofe) copper and Inconel 600. We also demonstrate that the primary effect of thermomechanical processing is to reduce or break the connectivity of the random grain boundary network. Samples of ofe $\mathrm{Cu}$ were subjected to a minimum of three different deformation paths to evaluate the influence of deformation path on the resulting GBCD. These include: rolling to $82 \%$ reduction in thickness, compression to $82 \%$ strain, repeated compression to $20 \%$ strain followed by annealing. In addition, the influence of annealing temperature was probed by applying, for each of the processes, three different annealing temperatures of 400, 560, and $800^{\circ} \mathrm{C}$. The observations obtained from automated electron backscatter diffraction (EBSD) characterization of the microstructure are discussed in terms of deformation path, annealing temperature, and processing method. Results are compared to previous reports on strainannealed ofe $\mathrm{Cu}$ and sequential processed Inconel 600. These results demonstrate that among the processes considered, sequential processing is the most effective method to disrupt the random grain boundary network and improve the GBCD.
\end{abstract}

\section{INTRODUCTION}

Watanabe first discussed "grain boundary design and control" in reference to the manipulation of the relative fractions of "special" and "random" boundaries in order to improve certain bulk materials properties [1]. Since that time, such manipulations have become known as grain boundary engineering. Grain boundary engineering has been demonstrated to be a viable means of improving certain properties of low to medium stacking fault energy FCC materials such as austenitic stainless and microalloyed steels [2,3], nickel and nickel-based alloys [2, 415], and lead alloys [16-18]. The susceptible properties are typically grain boundary controlled, such as corrosion and stress corrosion cracking [2, 4-18], creep and cavitation [19-22], and weldability [23].

Recent advances in grain boundary engineering have resulted from a number of factors. One of the most significant is the commercialization of a scanning electron microscopy (SEM) based technique to accurately and rapidly characterize crystal misorientations between grains in order to determine the GBCD [24-26]. Less than a decade ago, these misorientations were determined through time consuming transmission electron microscopy (TEM) or electron channeling within the SEM [27,28]. With automated EBSD hardware and software, it is now possible to acquire approximately 10,000 data points per hour, thus allowing characterization of a statistically significant number of grain boundaries in a reasonable time frame. Additional factors contributing to the recent advances in grain boundary engineering are reports by Palumbo et al. [2-13, 16-18] of the optimization of the GBCD through practical thermomechanical processing schedules and the recognition that improvements in the special fraction can play a crucial role in 
controlling the properties. A demonstration that boundary properties depend on misorientation has been presented in these proceedings by Bedrossian et al. [29] who have studied the susceptibility of individual grain boundaries to corrosion by coupling automated EBSD with atomic force microscopy (AFM). The AFM observations have identified the sites of localized attack observed in the EBSD as random grain boundaries. The deepest attack occurred at certain triple junctions composed of three random grain boundaries and no attack was observed at the $\Sigma 3$ boundaries. A number of observations of this type have revealed a correlation between misorientation and localized corrosion processes [29]. These findings, coupled with our recent experimental results, suggest that increasing the special fraction is a necessary, but insufficient condition to assure property improvements that depend on intergranular processes. This is because the GBCD is a scalar quantity and does not contain details of the connectivity of the random grain boundary network. In order to improve properties, it appears imperative that the random grain boundary network be disrupted, which is accompanied by an increase in the GBCD.

Research in the area of grain boundary engineering has concentrated on two primary thermomechanical-processing paths to improve the GBCD, strain annealing and strain recrystallization. Strain annealing typically involves low levels of strain (on the order of 3 to $7 \%$ ) followed by long annealing times. In the case of high-purity Ni studied by Thomson and Randle [14], strains of $6 \%$ followed by anneals for 168 hours were shown to modestly increase the special fraction. An additional benefit of the strain annealing lies in the "fine-tuning" of the misorientations to smaller deviations from the exact CSL description. Multiple, or repeated strain annealing treatments on ultrahigh-purity Ni-16Cr-9Fe were performed by Was et al. [15] to improve creep and cracking resistance. The improvement in the GBCD resulted from a two or three step deformation and annealing treatment. Tensile straining of 2 to $5 \%$ was followed by annealing at $890^{\circ} \mathrm{C}$ to $940^{\circ} \mathrm{C}$ for 1 to 20 hours. This process essentially doubled the number fraction of special boundaries from $16-20 \%$ in the solution annealed material to $26-43 \%$ in the specially processed case. It should be noted that the authors reported by number fraction and excluded coherent twin boundaries in their analysis, thus understating the total special fraction relative to other values in the literature reported by length fraction.

A fundamentally different approach to grain boundary engineering was taken by Palumbo and co-workers [2]. Their approach uses a sequential strain-recrystallization process to modify the grain boundary network. Typically, low to moderate levels of strain, in the range of 5 to $30 \%$ are followed by short anneals, on the order of $2-10$ minutes [2]. The annealing temperatures and times are chosen to allow recrystallization without subsequent excessive grain growth. This sequential processing is effective in producing a fine grain size, reducing texture, and increasing the special fraction. Palumbo et al. have reported significant improvements in properties including corrosion resistance, stress corrosion cracking, weldability, creep, and total elongation to failure [2-13, 16-18]. The present authors have studied strain-recrystallization in oxygen-free electronic (ofe) $\mathrm{Cu}$ and several Ni-based alloys. Successful sequential thermomechanical processing induces multiple twinning, that is the formation of twin-related variants or $\Sigma 9$ and $\Sigma 27$ boundaries [30,31].

The substantial improvements in the properties are most intriguing due to the potential transferability of the processing protocol to industrial settings. Typical metalworking practices start with ingot casting, generally followed by extensive forming steps used to reduce the ingot to usable forms such as bars, tubes, plates, or sheets. The thermomechanical processing sequences generally involve large deformation steps; with a minimum number of anneals to reduce the length of time, and thus overall cost of the forming process. Although this practice has been successful in producing quality products at affordable cost, recent work of Palumbo et al. [2-13, 16-18] indicates that significant improvements in many properties are possible with modifications to the processing schedules. This investigation focuses on evaluating the influence of processing method and annealing temperature on the resultant GBCD and connectivity of the random grain boundary network. 


\section{EXPERIMENT}

\section{Thermomechanical Processing}

A series of experiments was designed to evaluate the influence of annealing temperature and processing method on the resulting microstructure and GBCD. The starting material for the strain-annealing examination was Hitachi ofe $\mathrm{Cu}$ in the form of a 76-mm diameter by $152-\mathrm{mm}$ long bar with compositional analysis given in reference [30,32]. The 76-mm diameter bar was forged $55 \%$, annealed at $375^{\circ} \mathrm{C}$ for 4 hours, forged approximately $50 \%$, and then rolled to 9.5 $\mathrm{mm}$. The resultant disk was annealed at $375^{\circ} \mathrm{C}$ for one hour to induce full recrystallization. Strain annealing was performed by compressing samples between 6 and $7 \%$, followed by a relatively high temperature, long time, two-step anneal described in reference [33].

Strain recrystallization processing was performed on Inconel 600 and ofe $\mathrm{Cu}$. A slab cut from commercial purity Inconel 600 bar form was subjected to a thickness reduction of $20 \%$ per rolling sequence. After each deformation process, the slab was annealed at $1000^{\circ} \mathrm{C}$ for 15 minutes followed by water quenching. This sequential strain recrystallization processing sequence was repeated 7 times [30,34,35]. A series of strain-recrystallization processing schemes for ofe $\mathrm{Cu}$ were constructed to examine the influence of temperature and processing method on the resultant GBCD. One goal was to evaluate the influence of annealing temperature for the same level and paths of deformation. A second goal was to evaluate the difference between deformation by uniaxial compression and rolling. A third goal was to evaluate the effectiveness of sequential processing. Starting material for this series was ofe $\mathrm{Cu}$ bar, 38-mm in diameter and 76-mm long.

Three different processing schemes were devised. The first involved deformation by compression to $82 \%$ strain followed by annealing for ten minutes at one of the three temperatures, 400,560 , or $800^{\circ} \mathrm{C}$. All annealing treatments were performed in a box-type furnace in air. The second processing scheme involved deformation by rolling to $82 \%$ reduction in thickness followed by annealing for 10 minutes in air. The third processing scheme required multiple sequential deformations followed by annealing. The material was compressed $20 \%$ and annealed. This cycle was repeated to a total strain of $67 \%$. In addition, a fourth processing sequence comprised a single $20 \%$ strain by compression followed by an annealing treatment. The final processing scheme was a single $67 \%$ strain by compression with the same annealing treatment. The last two processing paths employed an annealing temperature of $800^{\circ} \mathrm{C}$.

\section{Characterization of the GBCD}

Automated EBSD was employed to characterize the GBCD and connectivity of the random boundary network. Individual orientation measurements are on a hexagonal grid at discrete points on the sample. At each point, the orientation is recorded along with coordinates describing the position. To evaluate the GBCD, misorientations between data points are calculated and then evaluated in terms of the Coincident Site Lattice Model [36,37] using the Brandon Criterion [38] for the acceptance angle. Maps are drawn using color, or thickness, of line to represent the type of boundary, special or random. The length fractions of special and random boundaries are reported for comparison purposes with literature reports. The random grain boundary network is analyzed by generating the CSL map, then removing the special boundaries. The resultant map reveals only the random grain boundaries, which can be evaluated in terms of connectivity of the network in two dimensions. 


\section{RESULTS AND DISCUSSION}

\section{Strain Annealing of OFE Cu}

Oxygen-free electronic copper was obtained in the form of 76-mm diameter bars with a starting grain size of about $125 \mu \mathrm{m}$. After processing the initial bar to plate material, the special fraction was approximately $70 \%$ with a grain size about 10 microns. Similar to the results of Thomson and Randle [14], the strain annealing process resulted in modest increases in the special fraction and tightening of the deviation from the exact CSL misorientation. The total special fraction approached $85 \%$ after $\sim 6 \%$ strain followed by annealing for $14 \mathrm{hr}$ at $275^{\circ} \mathrm{C}$ then $7 \mathrm{hr}$ at $375^{\circ} \mathrm{C}$ while increasing the grain size to 65 microns [33]. A number of drawbacks are evident from careful examination of this approach. First is the grain growth that occurs as a result of the long time anneals. The second drawback is a slight increase in texture that occurs as a result of this grain growth. Third is the presence of special boundaries, such as "island twins," that increase the observed length of special boundaries in the microstructure but do little to improve properties since they do not contribute to the grain boundary network.

\section{Strain Recrystallization Processing of Inconel 600}

Sequential strain recrystallization processing by rolling of Inconel 600 is quite effective in increasing the overall special fraction as shown in Figure 1a. As the number of processing sequences increases, the total special fraction, the fraction of $\Sigma 3$ boundaries, and the fraction of $\Sigma 3^{\mathrm{n}}$ boundaries increase. Most importantly, however, is the increasing ratio of $\Sigma 3^{\mathrm{n}}$ to $\Sigma 3$ that indicates multiple twinning events in the microstructure. This increase in the ratio of $\Sigma 3^{\mathrm{n}}$ to $\Sigma 3$ appears correlated with a disruption in the connectivity of the random grain boundary network as shown in Figure 1c. That, however, is only revealed when the GBCD is considered in terms of the frequency of occurrence, as the boundary length fraction of the low energy $\Sigma 3$ boundaries obscures the importance of other $\Sigma 3^{\mathrm{n}}$ boundaries like $\Sigma 9$ and $\Sigma 27$.

Evidence is now mounting for the argument that the connectivity of the random grain boundary network is the critical parameter in determining and predicting properties. One line of current research involves using sequential thermomechanical processing to disrupt the percolative paths in the material and quantitatively measuring the connectivity of the random boundary network $[34,35]$. To illustrate this point, the random grain boundary network has been extracted from the CSL maps as shown in Figures $1 \mathrm{~b}$ and $\mathrm{c}$ for the as-received material and the material processed five times. Although the grain size (including twin boundaries) of the alloy remains the same or slightly decreases as a function of processing, the network of random grain boundaries becomes sparse, and percolating paths through the structure break as the fraction of special boundaries increases.
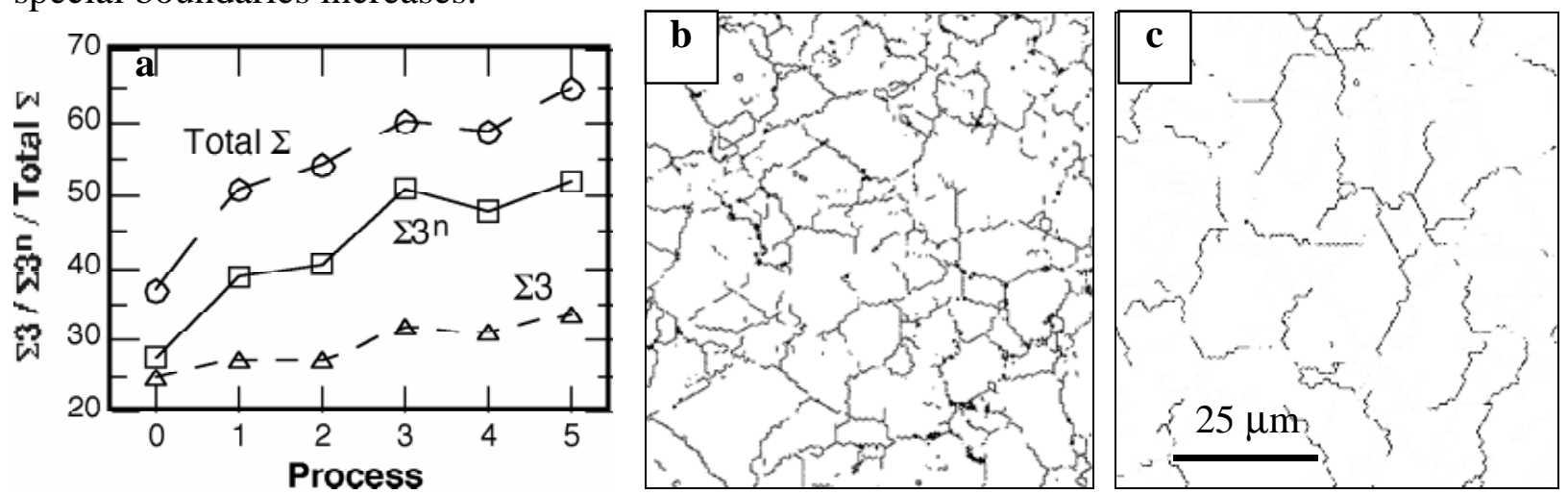

Figure 1. (a) Special fraction by frequency of occurrence as a function of processing number for Inconel 600, (b) random boundary network for the as-received Inconel 600, and (c) random boundary network for the material sequentially processed 5 times. 
On-going studies [31] using detailed TEM indicate that the breakup of the random boundary network may proceed by a boundary decomposition mechanism whereby, during the process of annealing, an immobile boundary can decompose into a lower energy configuration, one branch of which is presumably more mobile than the original boundary. Thus, new special boundaries can be introduced into a microstructure that in all likelihood aid in the break-up of the random boundary network.

\section{Strain Recrystallization Processing of OFE Cu}

Characterization of the GBCD in the as-received condition revealed a total special fraction of approximately $15 \%$. The fractions of $\Sigma 3, \Sigma 3^{\mathrm{n}}$, and total $\Sigma$ boundaries for ofe $\mathrm{Cu}$ processed in the $82 \%$ compressed form (labeled as 400-82), 82\% rolled form (400-P), and sequentially compressed and annealed at $400^{\circ} \mathrm{C}(400-\mathrm{S})$ are shown in Figure 2. Compression deformation to $82 \%$ followed by the 10 minute anneal at $400^{\circ} \mathrm{C}$ results in a total special fraction of about $56 \%$. The plate processing, i.e., rolling to $82 \%$ reduction in thickness followed by annealing produces a microstructure with approximately $57 \%$ special fraction. It is evident from this figure that sequential processing is the most effective in increasing the fraction of special boundaries. Nearly $70 \%$ of all boundaries are classified as special for this thermomechanical-processing route, an increase of approximately $15 \%$ over compression or rolling processing. As discussed above, one measure of the effectiveness of the processing is the ratio of $\Sigma 3^{\mathrm{n}}$ to $\Sigma 3$. This ratio is essentially constant for the $82 \%$ compression and rolling deformation, but increases for the sequentially processed material.

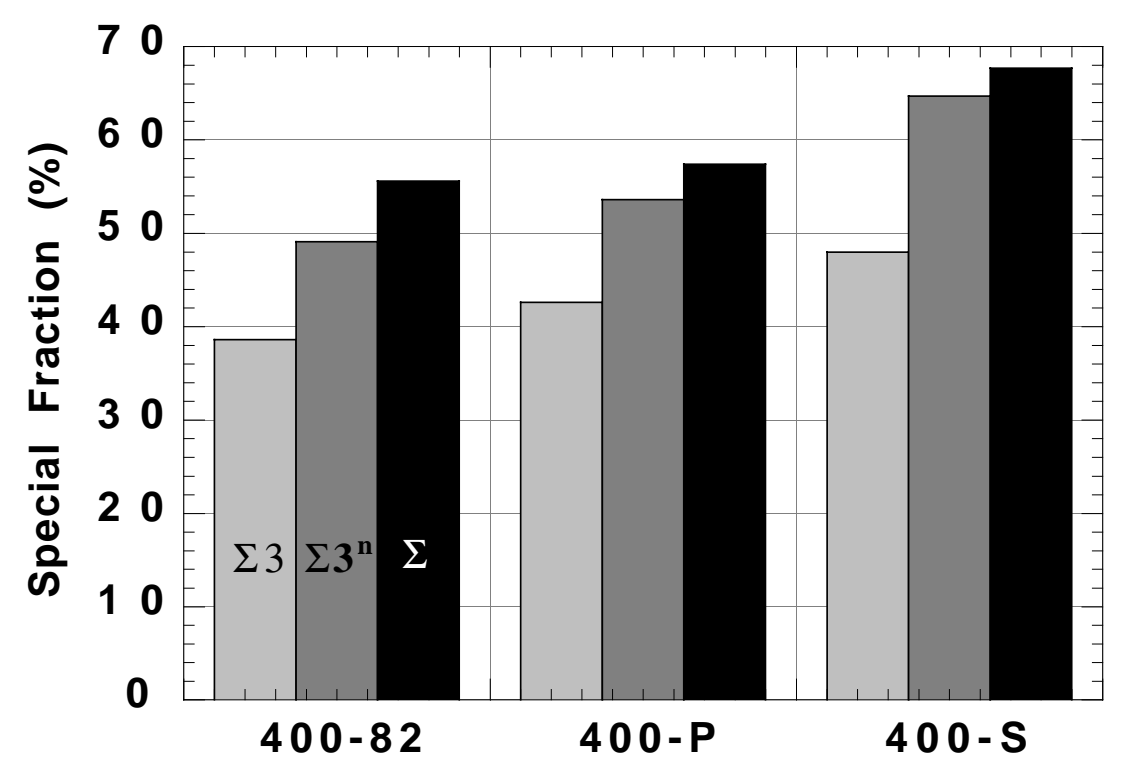

Figure 2. Special fraction as a function of processing scheme for the $400^{\circ} \mathrm{C}$ annealing temperatures indicates that sequential processing (400-S) improves the GBCD more effectively than compression deformation to $82 \%$ (400-82) or rolling to $82 \%$ reduction in thickness (400-P).

Figure 3 shows the CSL maps for the as-received ofe $\mathrm{Cu}$, as well as the 400-82, 400-P, and 400-S samples. Both the one-step rolled and compressed samples exhibit a relatively high fraction of $\Sigma 3$ boundaries located in the interior of the grains. However, interactions between individual twins are observed to be minimal. In contrast, sequential processing increases the ratio of $\Sigma 3^{\mathrm{n}}$ to $\Sigma 3$ through the mechanism of boundary decomposition and multiple twinning. These CSL maps are then processed to remove all special boundaries leaving behind only the 
random boundary network allowing a qualitative visual comparison of the connectivity. These images in Figure 4 reveal that the breakup in the connectivity of the random boundary network occurs only through sequential processing cycles.
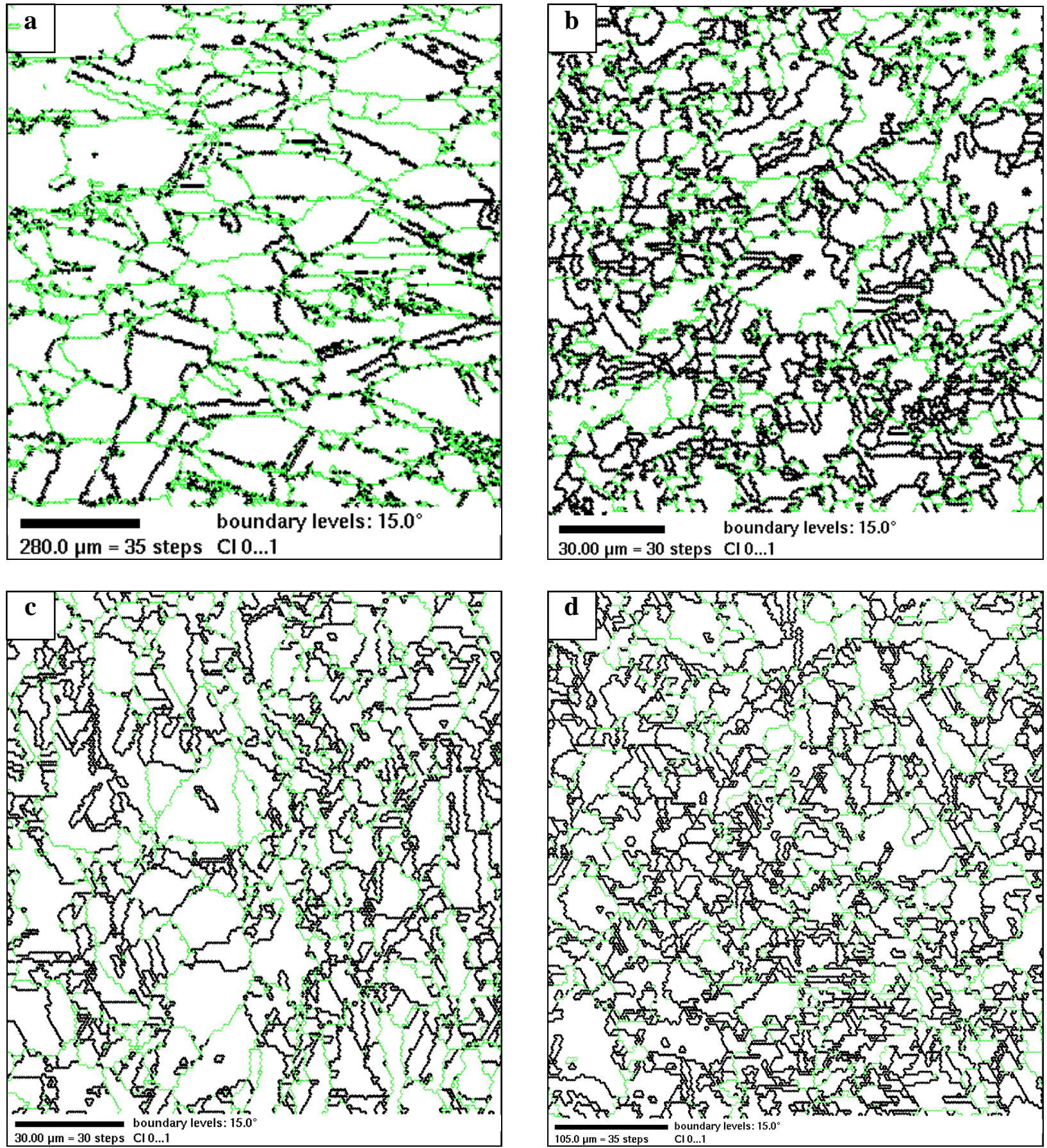

Figure 3. Special boundary maps for the ofe $\mathrm{Cu}$ processed at $400^{\circ} \mathrm{C}$. Special boundaries indicated as thick black lines, CSL boundaries indicated as thin gray lines. (a) As-received, (b) 400-82, (c) 400-P, and (d) 400-S 

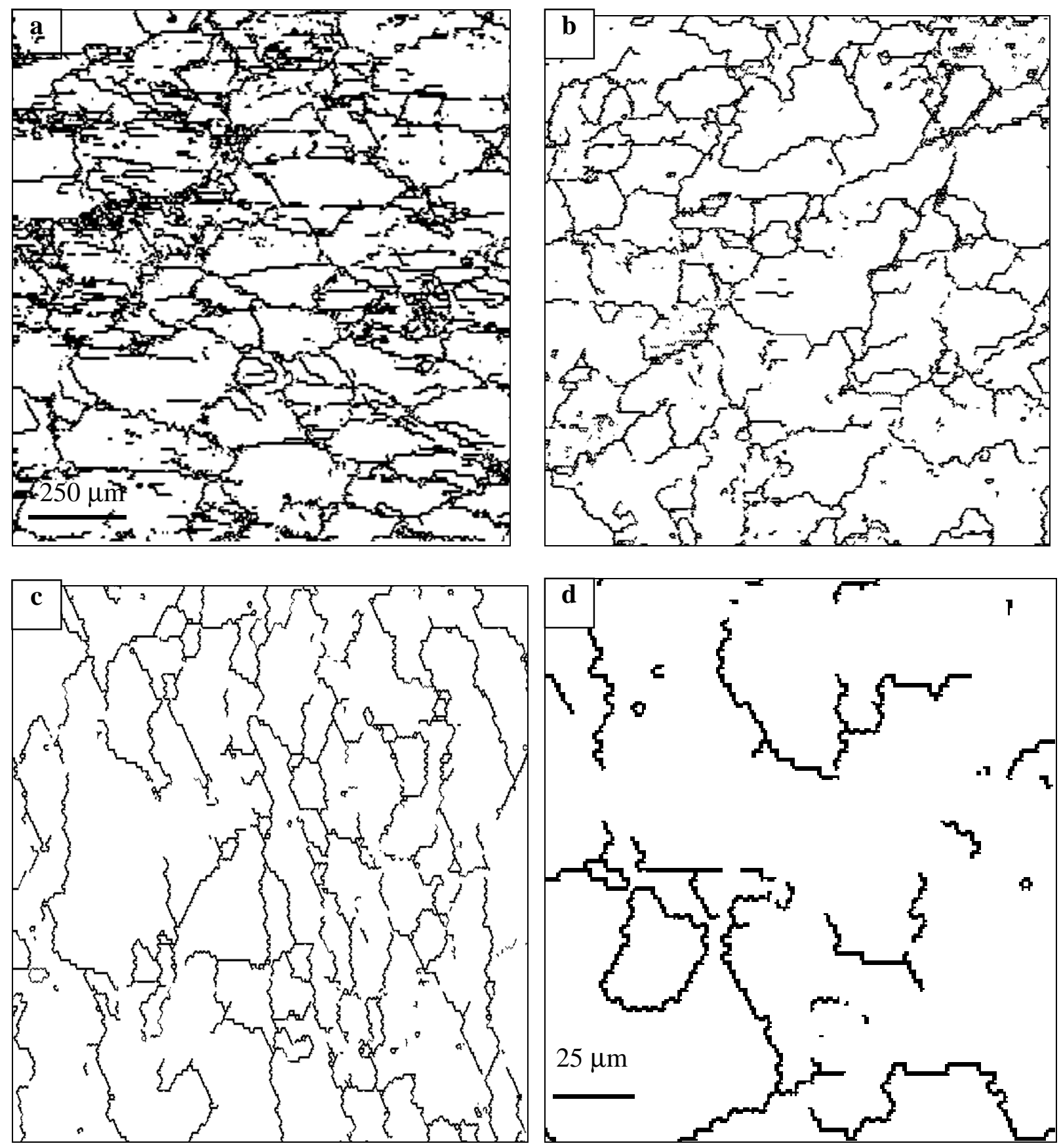

Figure 4. Random boundary maps extracted from the special boundary maps in Figure 3. (a) Asreceived, (b) 400-82, (c) 400-P, and (d) 400-S.

An additional effect was observed as a result of the sequential processing. The texture was observed to randomize during the sequential processing in agreement with [2]. Figure 5 shows two pole figures, the first from the as-received $\mathrm{Cu}$, and the second from the sequentially processed material. The texture is observed to decrease by a factor of two. 


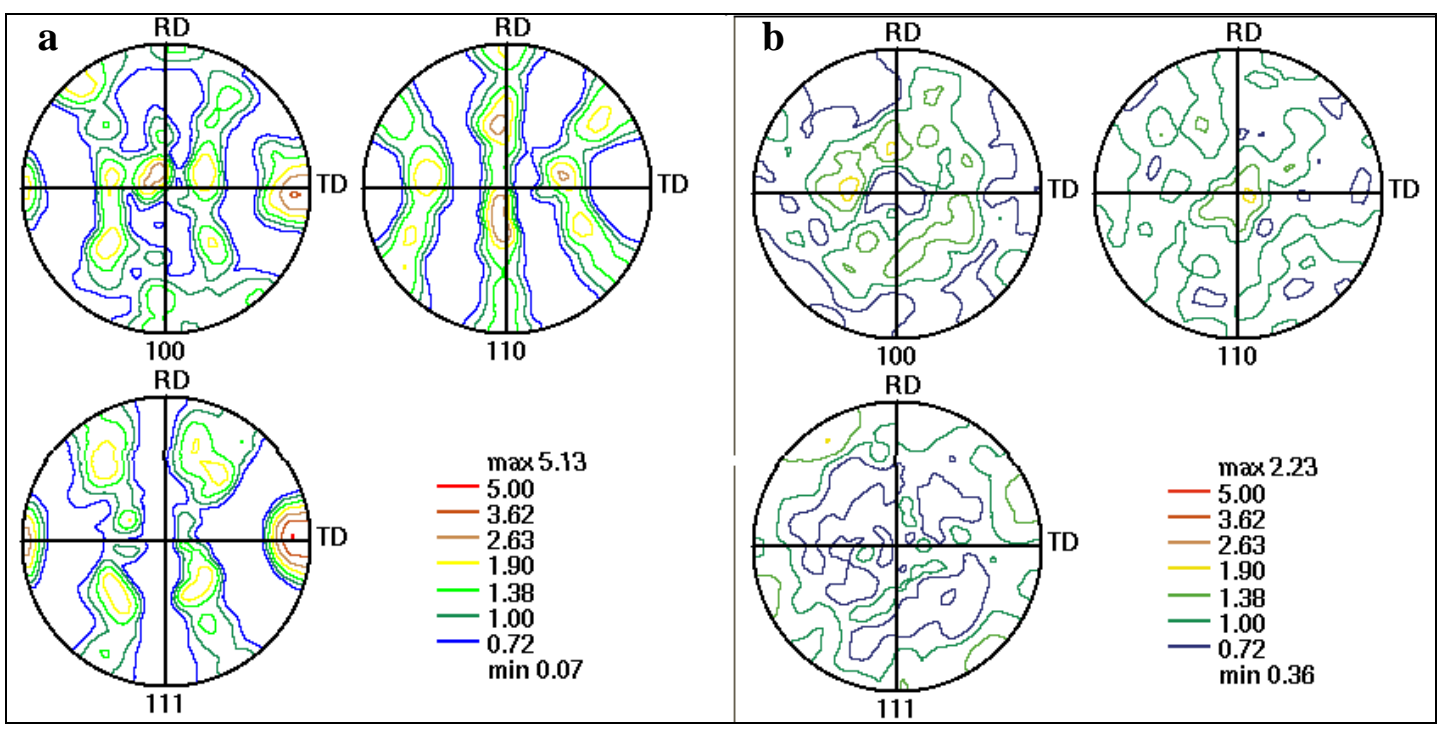

Figure 5. Pole figures of the (a) as-received $\mathrm{Cu}$ and (b) 400-S material. Texture is observed to decrease by greater than a factor of two.

Figure 6 shows a plot of the special fraction as a function of the processing scheme for an annealing temperature of $560^{\circ} \mathrm{C}$. The results at this temperature are similar to the $400^{\circ} \mathrm{C}$ annealing temperature in that the greatest increase in special fraction occurs during sequential thermomechanical processing. Sequential processing improves the special fraction by $16 \%$ over compression, and $10 \%$ over rolling.

The random boundary network was extracted from the special boundary maps as shown in Figure 7. These maps qualitatively reveal that a breakup in the connectivity of the random grain boundary network occurs only through sequential processing. Figure 7d shows the CSL map from the same region in the sequentially processed material (Figure 7c) and serves to demonstrate the mechanism by which boundary decomposition and multiple twinning disrupt the random grain boundary network.

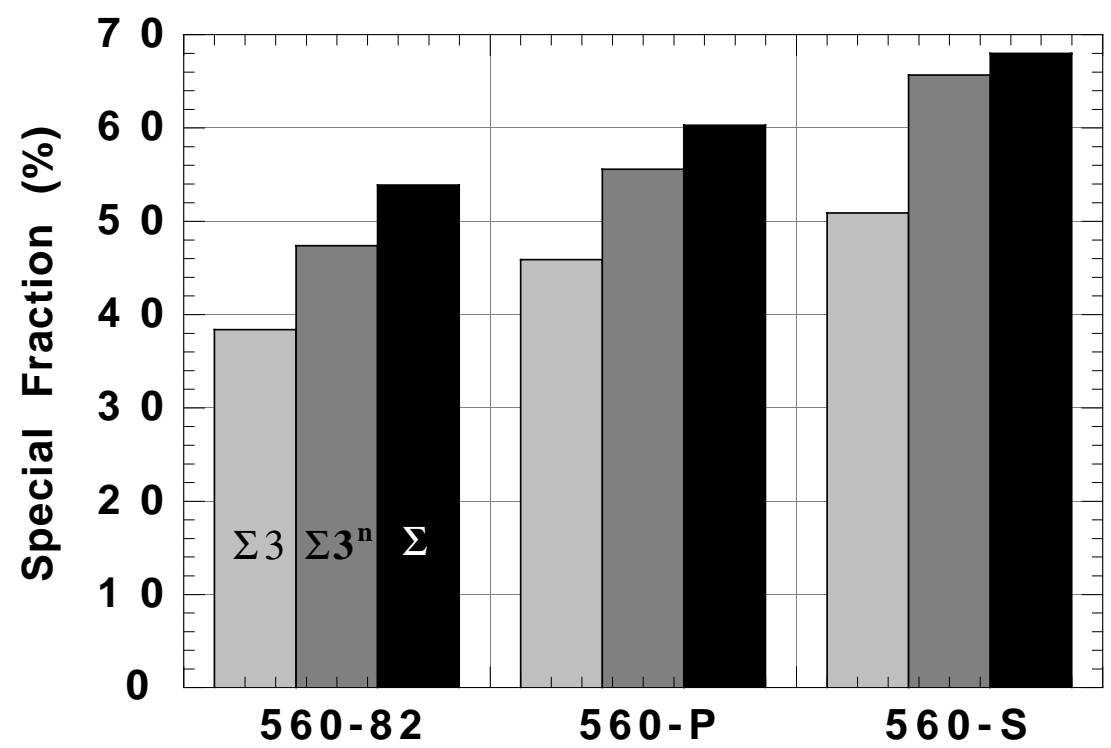

Figure 6. Special fraction as a function of processing scheme indicates that sequential processing (560-S) improves the GBCD more effectively than compression deformation to $82 \%(560-82)$ or rolling to $82 \%$ reduction in thickness $(560-\mathrm{P})$. 

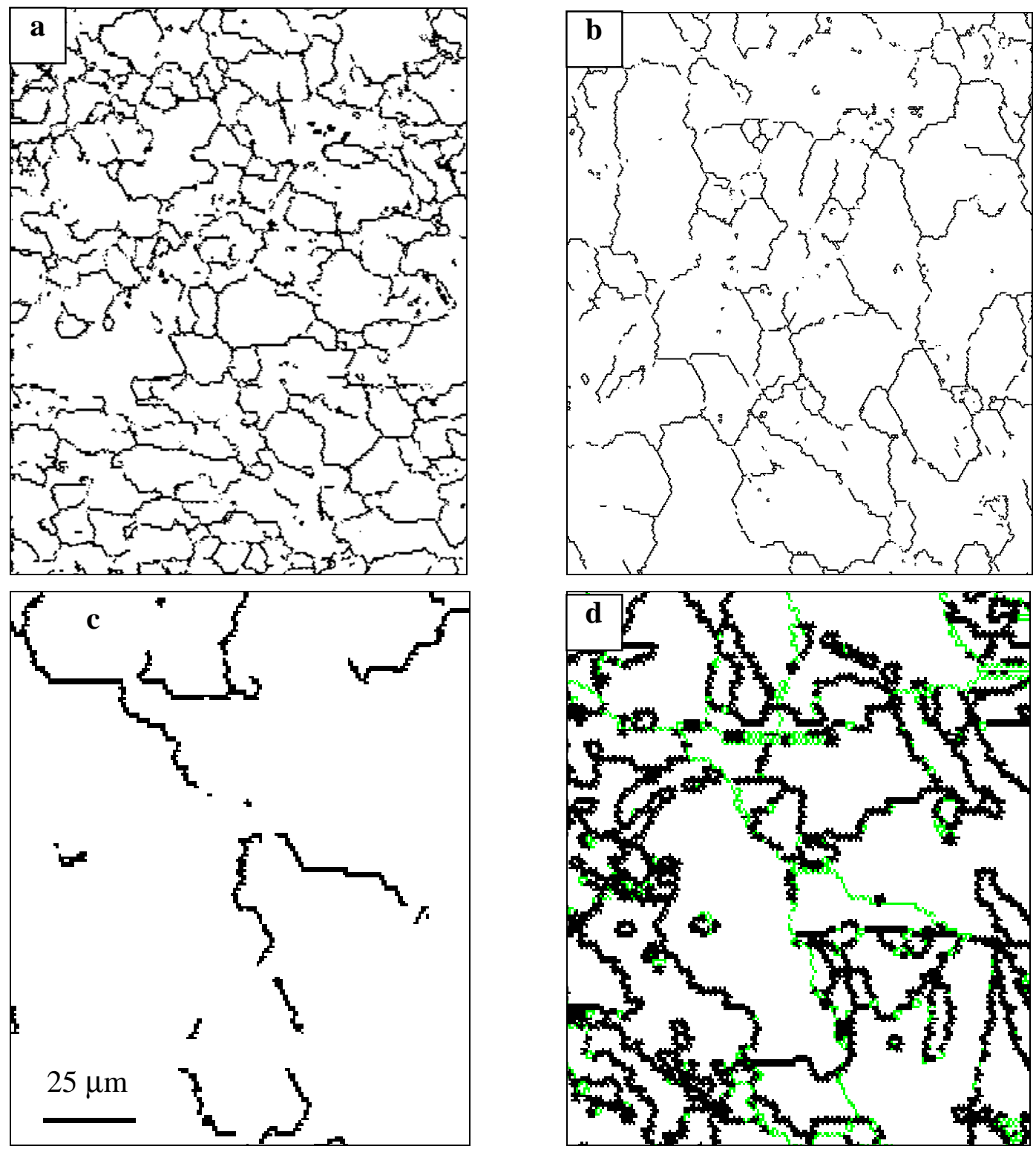

Figure 7. Grain boundary maps extracted from the special fraction maps in Figure 6. (a) 560-82, (b) 560-P, (c) 560-S, and (d), CSL boundary map from the same region as c with CSL boundaries in thick lines and random boundaries as thin lines.

The special fraction as a function of processing scheme for the materials annealed at $800^{\circ} \mathrm{C}$ is shown in Figure 8 and includes two other processes for comparison; one-step compression to $67 \%$ to match the total reduction of the sequential processing and one-step compression to $20 \%$. The random boundary maps shown in Figure 9 reveal imperceptible differences in the random boundary network. The microstructures resulting from annealing at $800^{\circ} \mathrm{C}$ differ from the lower temperature anneals in that the GBCD and random boundary connectivity are mostly insensitive to processing type. The average grain size of the materials deformed to $82 \%$ (800-82 and 800-P) is approximately $150 \mu \mathrm{m}$ indicating that grain growth following recrystallization dominates the evolution of microstructure. The sequentially processed material reaches a maximum special fraction of less than $60 \%$, nearly equal to all other processes. The average grain size approaches $100 \mu \mathrm{m}$, considerable less than in the $82 \%$ compressed or rolled material. Combined with the observation that sequential processing does not significantly disrupt the random grain boundary network in Figure 9c, this suggests that the microstructure essentially regenerates during each processing sequence. 


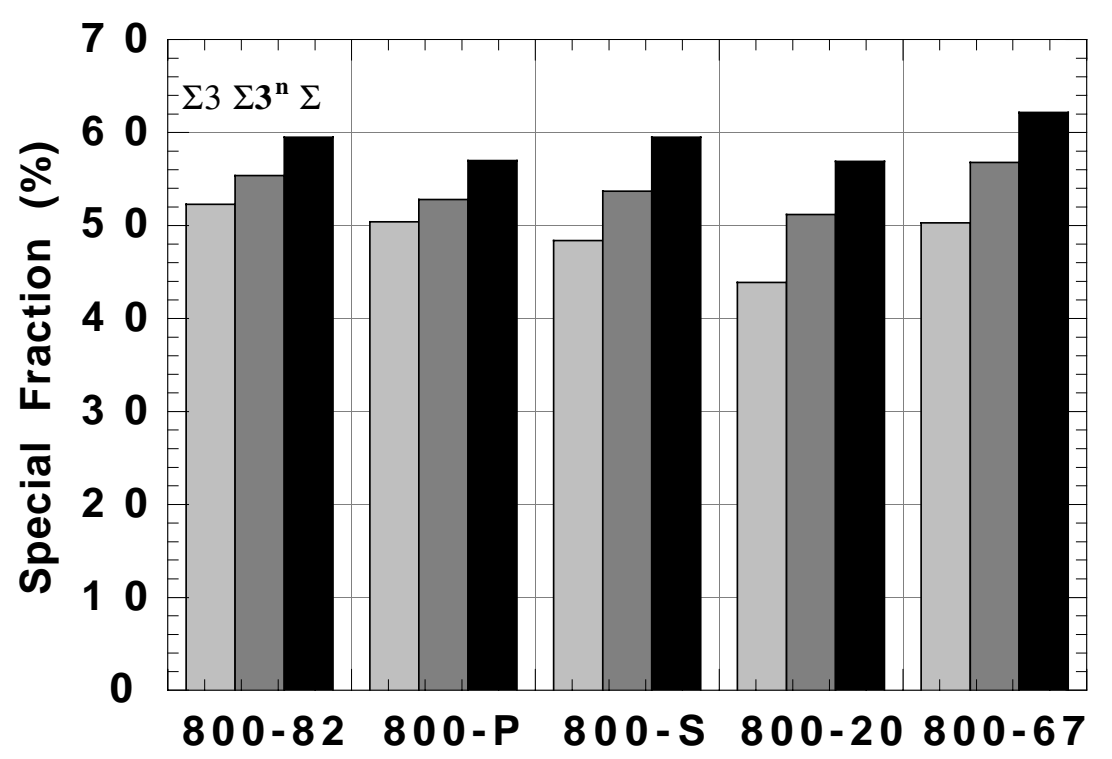

Figure 8. Special fraction as a function of processing scheme indicates that the GBCD is relatively independent of processing method at an annealing temperature of $800^{\circ} \mathrm{C}$.
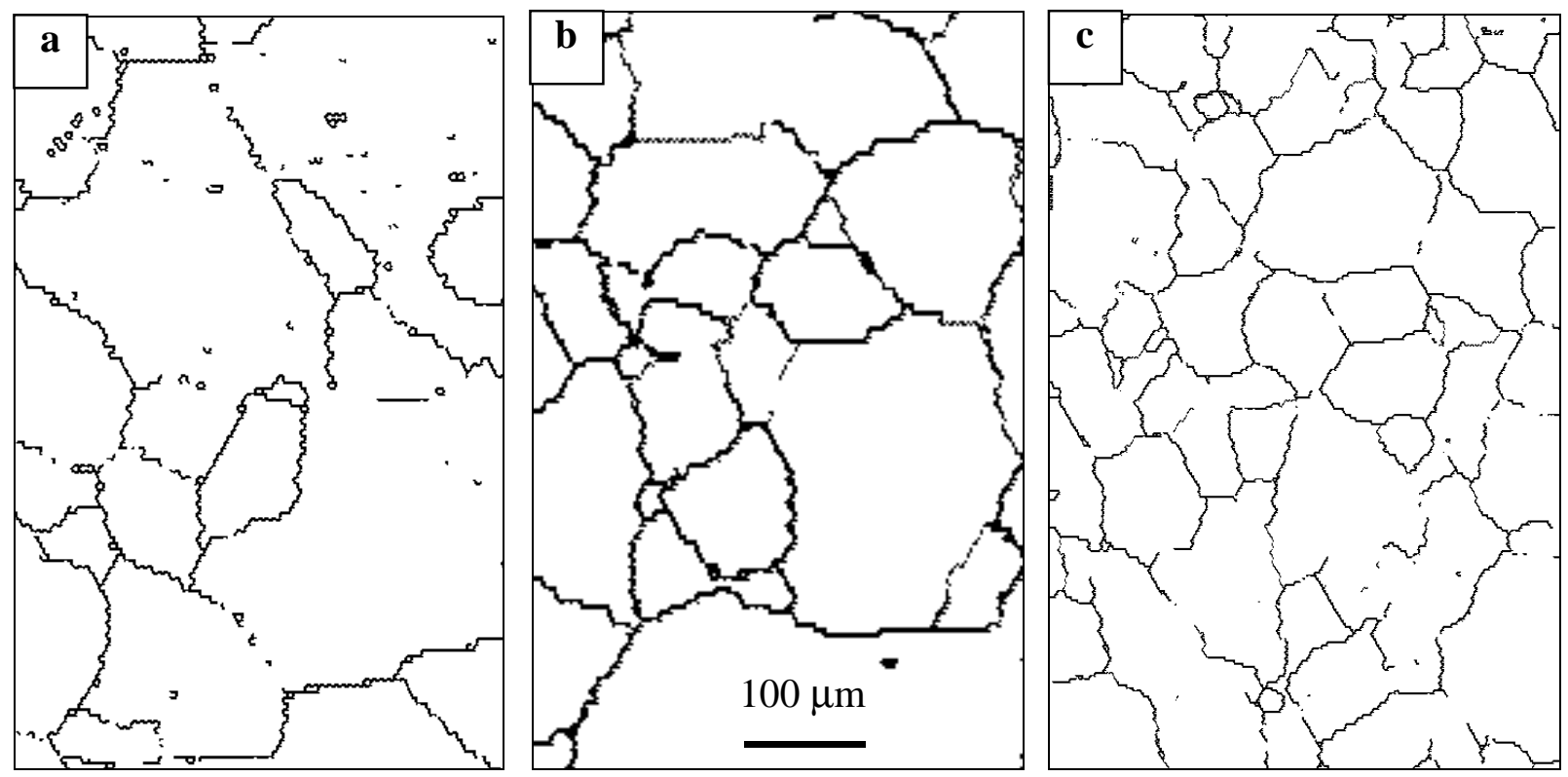

Figure 9. Random boundary maps extracted from the special boundary maps in Figure 8. (a) 800-82, (b) 800-P, and (c) 800-S.

A simple means of comparing the overall effects of temperature and processing method is summarized in Figure 10. The special fraction is plotted as a function of processing method and temperature. For both the $400^{\circ} \mathrm{C}$ and $560^{\circ} \mathrm{C}$ annealing temperatures, the sequentially processed material shows significant improvements in the GBCD over other processing methods. In addition, there appears to be little difference in the resulting special fractions between the deformation by rolling and compressive deformation processes.

The sequentially processed ofe $\mathrm{Cu}$ in this investigation was deformed by compression. Modifications to the GBCD through thermomechanical processing of Inconel 600 revealed similar improvements with sequential deformation by rolling [30,34,35]. It can be inferred from these two results that in order to improve the special fraction sequential and repeated deformation by rolling or compression followed by annealing is the most effective processing route. 


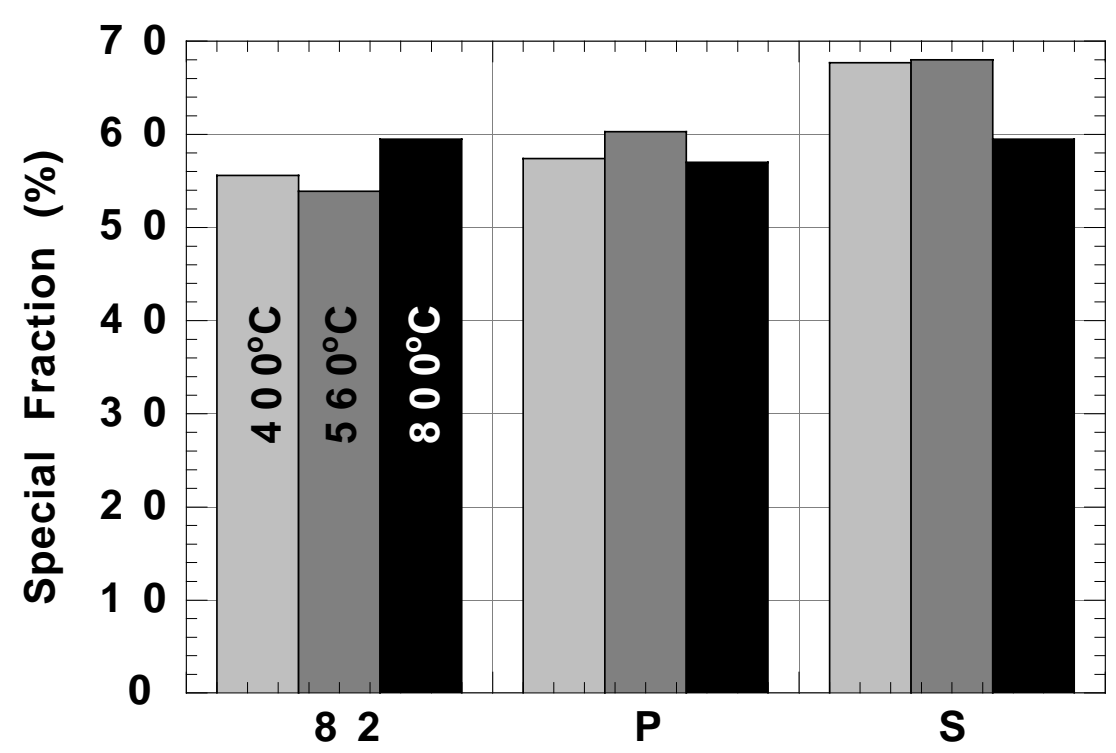

Figure 10. Special fraction as a function of processing scheme for the three processing temperatures and deformation schemes.

\section{CONCLUSIONS}

It has been demonstrated that both the deformation path and annealing temperature play a strong role in determining the connectivity of the random grain boundary network and GBCD. Compression deformation or rolling deformation to $82 \%$ strain increase the special fraction primarily through an increased fraction of annealing twins contained within the grains as evident from the relatively low ratios of $\Sigma 3^{\mathrm{n}}$ to $\Sigma 3$. This ratio, which shows a correlation to the connectivity of the random grain boundary network indicates that twin-twin interactions are a minimum. Sequential strain-recrystallization processing is much more effective than either onestep compression or rolling deformation in disrupting the random grain boundary network. This is clearly evident in the random grain boundary maps as well as the increased ratio of $\Sigma 3^{\mathrm{n}}$ to $\Sigma 3$. Annealing at $400^{\circ} \mathrm{C}$ or $560^{\circ} \mathrm{C}$ achieve similar disruptions of the grain boundary network and GBCDs after sequential processing. However, annealing at $800^{\circ} \mathrm{C}$ minimizes the influence of processing method due to the increased tendency for grain growth.

\section{ACKNOWLEDGMENTS}

The authors thank Ms. Lan Nguyen for the specimen preparation and some backscatter diffraction. This work is performed under the auspices of U.S. Department of Energy and Lawrence Livermore National Laboratory under contract No. W-7405-Eng-48.

\section{REFERENCES}

1. T. Watanabe, Res. Mechanica 11, p. 47 (1984).

2. G. Palumbo, Thermomechanical Processing of Metallic Materials, US Patent 5,702,543 (1997) and Metal Alloys Having Improved Resistance to Intergranular Stress Corrosion Cracking, US Patent 5,817,193 (1998).

3. E.M. Lehockey, G. Palumbo, and P. Lin, Scripta Materialia 39, No. 3, p. 353 (1998).

4. G. Palumbo and K.T. Aust, Materials Science and Engineering A113, p. 139 (1989).

5. G. Palumbo and K.T. Aust, Acta Metall.Mater. 38, No. 11, p. 2343 (1990).

6. G. Palumbo, P.J. King, K.T. Aust, U. Erb, and P.C. Lichtenberger, Scripta Met. 28, No. 8, p. 1775 (1991). 
7. K.T. Aust, U. Erb, and G. Palumbo, Materials Science and Engr. A176, p. 329 (1994).

8. P. Lin, G. Palumbo, U. Erb, and K.T. Aust, Scripta Mat. 33 No. 9, p. 1387 (1995).

9. C, Cheung, U. Erb, and G. Palumbo, Materials Science and Engr. A185, p. 39 (1994).

10. G. Palumbo, E.M. Lehockey, P. Lin, U. Erb, and K.T. Aust in Interfacial Engineering for Optimized Properties, edited by C.L. Briant, C.B. Carter, and E.L. Hall (Mater. Res. Soc. Proc., 458, Pittsburgh, PA 1997), p. 273-282.

11. E.M. Lehockey, G. Palumbo, P. Lin, and A. Brennenstuhl, Microscopy and Microanalysis, G.W. Bailey, J.M. Corbett, R.V. Dimlich, J.R. Michael, and N.J. Zaluzec, Eds. p. 346 (1996).

12. G. Palumbo, E.M. Lehockey, P. Lin, U. Erb, and K.T. Aust, Microscopy and Microanalysis, G.W. Bailey, J.M. Corbett, R.V. Dimlich, J.R. Michael, and N.J. Zaluzec, Eds. p. 362 (1996).

13. E.M. Lehockey and G. Palumbo, Materials Science and Engr. A237, No. 2, p. 168 (1997).

14. C.B. Thomson and V. Randle, Acta Mat. 45, No. 12, p. 4909 (1997).

15. G.S. Was, V. Thaveeprungsriporn, and D.C. Crawford, Journal of Metals, 50, No. 2, p. 44 (1998).

16. E.M. Lehockey, G. Palumbo, A. Brennenstuhl, and P. Lin in Interfacial Engineering for Optimized Properties, edited by C.L. Briant, C.B. Carter, and E.L. Hall (Mater. Res. Soc. Proc., 458, Pittsburgh, PA 1997), p. 243-248.

17.E.M. Lehockey, G. Palumbo, P. Lin, and A. Brennenstuhl, Metallurgical and Materials Transactions 29A, p. 387 (1998).

18. E.M. Lehockey, A. Brennenstuhl, G. Palumbo, and P. Lin, British Corrosion Journal 33, No. 1, p. 29 (1998).

19. J. Don, S. Majumdar, Acta Metallurgica 34, p. 961 (1986).

20. D.P. Field, B.L. Adams, Acta Metallurgica et Materialia 40, p. 1145 (1992).

21. V. Thaveeprungsriporn and G.S. Was, Metallurgical and Materials Transactions 28A, p. 2101 (1997).

22.E.M. Lehockey, G. Palumbo, P. Lin, and A.M. Brennenstuhl, Scripta Mat. 36, p. 1211 (1997).

23. E.M. Lehockey, G. Palumbo, and P. Lin, Metallurgical and Materials Transactions 29A, p. 3069 (1998).

24. B.L. Adams, S.I. Wright, and K. Kunze, Metallurgical Transactions 24A, p. 819 (1993).

25. T.A. Mason and B.L. Adams, Journal Of Metals 46, No. 10, p. 43 (1994).

26. S.I. Wright, J. Computer-Assisted Microscopy 5, No. 3, p. 207 (1993).

27. T. Watanabe, Philosophical Magazine A47, p. 141 (1983).

28. T. Watanabe, Microscopy and Microanalysis, Ed. By G.W. Bailey, J.M. Corbett, R.V.N. Dimlich, J.R. Michael, and N.J. Zaluzec, p. 354 (1996).

29. P.J. Bedrossian, A.J. Schwartz, M. Kumar, and W.E. King, this proceedings.

30. M.Kumar, A.J. Schwartz, and W.E. King, in Advances in Twinning, edited by S. Ankem and C.S. Pande, (TMS, Warrendale, PA 1999), p. 13.

31. M. Kumar, A.J. Schwartz, and W.E. King, Presented at the MRS Fall Meeting, Boston, MA (1999)

32. A.J. Schwartz and W.E. King, Journal of Metals 50, No. 2, p. 50 (1998).

33. W.E. King and A.J. Schwartz, Scripta Mat. 8, No. 3, p. 449 (1998).

34.M. Kumar, A.J. Schwartz, and W.E. King, Proceedings of the Twelfth International Conference on Textures of Materials, J. Szpunar, Ed. (Canadian National Research Council Press), p. 180 (1999).

35. M. Kumar, W.E. King, and A.J. Schwartz, submitted to Acta Materialia (1999).

36. M.L. Kronberg and F.H. Wilson, Transactions of the AIME 185, p. 501 (1949)

37. H. Grimmer, W. Bollmann, and D.H. Warrington, Acta Cryst. A30, p. 197 (1974).

38. D.G. Brandon, Acta Metallurgica 14, p. 1479 (1966). 